\title{
SOME PRACTICAL OBSTACLES IN MODIFYING GOVERNMENTAL STRUCTURE TO MEET METROPOLITAN PROBLEMS
}

\author{
Lennox L. Moak $\dagger$
}

\section{The "Metropolitan Problem"}

There is perhaps no governmental subject about which there is so much currently written, so much concern, and so little understanding as the "metropolitan problem." Numerous efforts have been made to define it. Among the better ones, we find some fine phrases which together encompass the total gamut of human existence. I doubt that we can afford so all-inclusive a definition.

For purposes of this paper, I use the term metropolitan problems to mean:

Those problems of governmental significance occurring in two or more legally coordinate governmental jurisdictions at the local level which require joint or cooperative action for their most rational solution. Such jurisdictions must be situated in an area in which there is a primary orientation of economic and social activities to a common center.

It is not necessary that the problem exist in each of the jurisdictions, or even in a majority of those composing an area for it to become metropolitan in character. Thus, ten jurisdictions out of 500 in a metropolitan area may have a basic water supply problem. If these ten jurisdictions are important to the metropolitan complex, and if the solution of the problem requires either joint or cooperative action, it qualifies as a metropolitan problem. However, most metropolitan problems encompass a much larger percentage of the jurisdictions of the area.

Unfortunately, students working in the metropolitan field have reached little or no agreement as to just what they are trying to remedy. This situation arises in large measure from the lack of widespread

$\dagger$ Director, Bureau of Municipal Research (Philadelphia) and Pennsylvania Economy League, Eastern Division. Formerly Director of Finance, City of Philadelphia. B.S., 1932, Southwest Texas State College; M.A., 1940, University of Texas. 
scientific attack in the determination of which aspects of organization of governmental activities require modification.

I assume that we are in search of improved methods for the performance of certain common services-both public and private. But I also assume that we are here concerned only with those which are performed by or significantly regulated by public agencies. Thus, while the support of a symphony orchestra may be an important community activity which cuts across many legal jurisdictional lines, it is not a "metropolitan" problem unless it becomes a governmental or governmentally-sponsored enterprise. Conversely, the exercise of the police function is metropolitan at least in some degree because of the necessity for cooperation between publicly constituted law enforcing agencies.

The objective of this paper is to discuss some of the practical problems involved in adjusting governmental structure for a more rational performance of governmental functions in the solution of metropolitan problems. The list of such problems is long. In fact, it is so long that the writer cheerfully admits he has neither the patience, experience nor competence to discuss all of them at this time. But he believes that any discussion of problems is conditioned by at least the two following factors:

(1). The system of values. Prerequisite to a comprehensive discussion of practical problems would be a determination of a system of values to be used in judging ultimate solutions. Any such system would involve not only very tangible items such as effectiveness, efficiency and economy in management of public affairs but also, if one should want to become deeply involved in philosophy, some agreement upon the very ends of human existence.

(2). Structure itself. The nature of structural arrangements sought for a solution of metropolitan problems within themselves carries the determinant of the degree to which certain specific problems discussed below are applicable. Obviously, a different set of problems would be involved in achieving minor structural modifications for cooperative contracting between units for performance of services as contrasted with any effort at a wholesale consolidation similar to that which took place in Philadelphia County in 1854.

A full paper could be developed on the value system but we must short circuit this process here, leaving only inferences of possible elements in value system as they evolve from discussion of the problems. Even inferences are subject to challenge as each reader doubtless has 
his own value system and, should he be writing this paper, he might develop the same concepts quite differently.

With respect to structure, if the consideration of metropolitan problems is to proceed on a logical basis, we must first determine the specific problems for which solutions are required. Secondly, we must review, on a problem-by-problem basis, the best theoretical solution to each problem-including the best structural arrangement. For a single problem this theoretical solution may be relatively easy to determine. But even upon a theoretical basis, complications arise as we attempt to reconcile and adjust a dozen or more different theoretically most desirable structural solutions for a corresponding number of metropolitan problems. Thus, if one of the metropolitan problems is basic water supply for half of the area, and another is transit for twothirds partially overlapping the first, and deep-water transportation problems involve directly only a few units, we begin to see that the reconciliation of a variety of theoretical solutions for individual metropolitan problems is far from easy.

\section{Possible Structural CHanges in Governmental Organization}

In the course of arriving at the theoretical solutions best suited to the problem, one must resolve the question as to whether he will undertake to rely upon cooperative action by existing governmental units-for example, there are several hundred within the Philadelphia metropolitan area of eleven counties. Is the cooperative approach really feasible in the light of the manifold considerations? The machinery for achieving and carrying into execution a solution to any number of common problems on a cooperative basis would doubtless break down before getting into motion. Moreover, the history of effective cooperation on a problem by problem basis among so numerous a group of units is not encouraging as a basis upon which to proceed.

If not on the basis of cooperation among existing units, then other possibilities include transfer of some municipal powers to the eleven counties and trying cooperation between a lesser number of units on a county-unit basis. ${ }^{1}$ The prognosis for success would doubtless be greater than with hundreds of units, but the lack of integrated and legally enforceable action would still be a real impediment.

The possibility of one or more federations suggests itself and requires careful exploration. The nature of the federations and the kind of machinery would do much to determine their usefulness in a practical solution to common problems.

1. The author significantly omits consolidation on any area-wide basis as both theoretically undesirable and practically unattainable. 
Among the possibilities to be explored would be that of greater reliance upon either special or general purpose authority-type organizations created through compacts between the existing jurisdictions. But again, in order to hold the number of participants to some manageable group, devices for consolidation of some functions at least at the county level would be indicated as a prerequisite to negotiation of practical compacts on a local basis.

Compact arrangements could, of course, take on a state-to-state relationship with the states superseding their local units in the negotiations and determination of structure, powers and functions to be performed. Interstate compacts heretofore negotiated generally provide only for representation at the state level, leaving the local interests to shift for themselves through political or informal means to achieve any effective degree of representation of local interests in such interstate agencies dealing with essentially local problems.

Within the realm of structural possibilities is that of the creation of a new level of government which would be above the county and below the state. It could be operative within the boundaries of a single state or on a bi- or tri-state basis under negotiated and approved interstate compacts. It could be endowed with fundamental powers in the same manner in which townships, boroughs, cities and counties are so endowed today. It could provide for either direct popular representation or indirect representation in its governing authority. It could be assigned specific functions on a region-wide basis or gradually assigned such functions as the local governmental units deemed appropriate to transfer to it for performance.

In the matter of determining structure, a primary value to be considered is the method of maintenance of popular control at essential points. Practical politicians may momentarily scoff at the theory of popular control. But in the long-term view there is nothing more fundamental in the development of American public life than the insistence and ultimate achievement by the public of popular control over public business. Witness the fact that the Constitution of the United States, as originally adopted, sought to place the Senate and the Presidency beyond popular control. While it took a long time, it is clear that today both the Senate and the Presidency are organs representing the people directly. The people would not tolerate a system under which the Senate could be chosen by state legislatures with consequent possibilities for an unresponsive, irresponsible and unrepresentative Senate. Nor did they long permit the electoral college to be chosen or to function in the manner originally intended by the constitutional framers. 
In like manner, the people of Britain have converted their Parliament into an instrument of effective popular control.

Therefore, while short-term solutions, such as inter- or intrastate authorities removed from positions of popular control, may flourish, this writer is of the opinion that the people will devise and force upon their elected officials the means for popular control of instrumentalities performing important public functions. Such control may take the form of direct popular election, or it may take some other form of political invention. But the architect of any plan for solution of metropolitan problems upon a permanent basis is confronted with, and I think must solve, the question of how popular control is to be made effective.

\section{Obstacles to Structural Change}

Clearly the determination of structure upon both a theoretical and practical basis constitutes a significant problem and the solution will not be developed by formula or without study and experimentation. In any event, assuming that the desirable solution requires a substantial degree of structural change, numerous problems, or obstacles, block the road to achieving the change. Any list of those problems would include as a minimum the following, and some would include many more:

(1). Legal-constitutional and statutory problems, interplay of forces in legislative bodies, and inter-state character of some actions required.

(2). Political-theory of popular control, present pattern of party control of local governmental units, importance of a "place in the sun" for local political leadership in officialdom, and closeness to the people.

(3). Fiscal.

(4). The vested interest-public officials and employees, those who profit from business arrangements, those who enjoy or think they enjoy special tax or other privileges.

(5). Emotional-apathy, pride, fear and jealousy.

(6). Communication.

(7). Plain Cussedness.

\section{Legal}

A separate paper is included in this symposium on legal problems in rearranging structure. ${ }^{2}$ I shall not undertake to transgress upon this

2. Miller, Metropolitan Regionalism: Legal and Constitutional Problems, 105 U. PA. L. Rev. 588 (1957). 
treatment in the normal context; however, I am impelled to some remarks on this point.

We have succeeded in creating for the conduct of our public business a legal structure which is so inflexible that if imposed in the conduct of our private affairs it might well spell our sudden economic and social death. It is highly significant in most of our activities as citizens of a nation or state that we proceed back and forth across this nation, across state lines, across minor civil jurisdictional lines with little or no consciousness of their existence. Thus, except for payment of certain state and local taxes, and conformity to certain legal formalities, if one chooses to earn his living by producing and marketing hairpins, he may organize his venture with little regard to political and jurisdictional lines.

Likewise, a great national or international steel corporation may with few inhibitions seek a rational organization of its activities within national boundaries. While state and local taxes and regulations affect a determination of where certain elements of the industry are to situate, the corporation is virtually without legal restraint as to where to establish the various elements of its operations. Moreover, either the hairpin company or the steel company can with great flexibility adjust and readjust its corporate structure as the management deems will best contribute to the achievement of the objective of the respective company. As a matter of fact, the hairpin and steel companies may merge, or either of them may create subordinate corporations as appear desirable.

Even in the operation of national transportation systems, which are heavily regulated by various levels of government, the regional or national character of the corporate structure makes possible the carrying out of functions across minor or major legal jurisdictional lines with a minimum concern for such lines.

But if we take any one of the foregoing functions, particularly that of manufacturing hairpins or steel, and consider transferring their ownership and management from private to public control, a host of problems immediately arises. Among the more important of these are: (a) To what level-national, state or local-is the assignment to be made? (b) If assigned to a local or state unit, how do we achieve the necessary framework for cooperative or joint action with other coordinate units necessary for effective and economical performance of the function? (c) How are charges to be apportioned? If there is a profit or a loss who is to share? (d) What shall be the means by which the newly acquired public function is to be controlled in order to meet our traditional concepts of keeping governmental activities in 
a position of responsiveness and responsibility to our elected representatives-both executive and legislative?

In all of these matters, we would be confronted with a host of legal requirements and inhibitions. Private business frequently complains, and sometimes with much justice, about restrictions upon freedom involved in the conduct of business. Yet, comparatively, they have the freedom of an eagle in flight, while public jurisdiction must seek some practical route through a maze of legalisms in order to come to any kind of workable answer.

It is appropriate here to call attention only to the general breadth of the legal structure and to mention that the entire theory of our legal system-based upon a tradition of tradition-loads the dice heavily in terms of maintenance of stability and, therefore, of the status quo. None of these legal obstacles is insurmountable in the face of protracted attack, but they are legion. The fact that we can do almost nothing within the present framework may prove beneficial in that it will help to create the crisis conditions frequently essential to solutions of public problems, rather than mere painless and transitory adjustments.

\section{Political}

Except for the careful student of public affairs, few persons are able to place matters to which the word "political" is attached in even a reasonably adequate frame of reference. Few words in our vocabulary are more loaded and likely to bestir stereotypes than is the word "political." And unfortunately the images thus conjured range through the widest spectroscope projection.

Despite this, the political problems are of great importance. If we look, for example, at the five Pennsylvania counties in the Philadelphia metropolitan area, we find a host of political considerations and conditions which help to identify the following practical political problems in achieving a solution to problems of metropolitan governmental structure.

\section{Party Control}

One of the most obvious items is the present distribution of party control of the formal governments operating in the area. At the state level, the Governor is Democratic and both houses of the legislature are controlled by the Republicans. Philadelphia City (and former county) offices are almost all controlled by the Democrats. Majority control at the county level in Bucks County appears to be in a state of flux; Chester, Delaware and Montgomery Counties are all firmly Republican. 
At the borough and township level, a few units are controlled by the Democrats, but the great majority in the four counties is in the hands of the Republicans. Examination of votes for the entire fivecounty area in recent state and national elections shows that the two parties-on the entire area basis-are fairly well balanced. But within specific jurisdictions, control by one or the other party is frequently so firm as to set up a resistance to merging in any way with larger units because of the risks assumed of losing control-both personal and party.

\section{A Personal Place in the Sun}

The importance of personal recognition and prestige on a local basis is a factor frequently not understood, or under-rated, by those who have occasion to consider political conduct.

Public office, particularly at the township and borough level, affords at least 4,000 citizens in the four Pennsylvania counties nearest Philadelphia an opportunity for direct public service as elected public officers-councilmen, commissioners, tax collectors, attorneys, et al. For many of these it is a public service undertaken as public duty with little hope or desire for recognition or reward beyond that of a public service.

But for a large number of such office holders, the office is a matter of personal prestige for the holder. Moreover, frequently it is both a source of current employment and potential advancement either politically or from the viewpoint of remuneration. Those office holders, and at least an equal number who aspire to replace those now in office, constitute a potent group with an interest in the maintenance of the status quo. They tend to view with suspicion any proposal for change-whether in the broad interest of solution of metropolitan problems or in wholly local matters of more effective and efficient organization for performance of governmental functions at presently assigned levels.

\section{The Big, Bad City}

Many smaller jurisdictions in a metropolitan region enjoy a remarkable degree of freedom from corruption in the performance of public functions, and some of them enjoy this over long periods of years. Conversely, the big city is almost a stereotype for corruption in the handling of public business. It is there that the great political machines have evolved, disintegrated, and been born again during the past three generations. There is a strong reluctance on behalf of many suburban communities to become involved with this stereotype of evil- 
the big city. The fact that there may be equally potent local political machines, and sometimes equally corrupt, does not appear to lessen concern in any significant degree.

\section{Keep Government Close to the People}

Aside from the foregoing, there is both a real and specious argument that is advanced with regard to keeping government close to the people.

On the specious side, many officials and other self-interest groups argue that transfer of functions to larger governmental units, whether through merger or creation of new levels or instrumentalities, has the effect of rendering popular control impossible. Clearly, we have, through our large cities and our state and national governments, demonstrated that size within itself does not necessarily mean that popular control is lost when government is performed not so close to the people. While these arguments are frequently advanced with great sincerity, the independent observer sometimes wonders to what degree such arguments-when advanced by public officials-are not in large measure a smoke screen to cover up less laudable ambitions or considerations.

On the other hand, any keen, independent observer sees that public participation in community affairs-beyond the formal balloting stage-is perhaps deeper in the small community than in the larger cities. Thus, there is more frequently a personal knowledge of the strictly local developments in a medium or even large township or borough than in a city the size of Philadelphia. Officials are known on a personal basis to a larger percentage of the people. Teachers and school administrators are more likely to be neighbors. Any public problem-a sewer, bridge, firehouse or school-receives direct attention and some community participation in the planning process to a greater degree than in the large city. For a variety of reasons schools are frequently better in the medium size suburb than in the very small or very large jurisdictions in the region.

Hence, he who would solve metropolitan problems is confronted with a most practical problem in assaying the values to be derived from keeping the government close to the people against the apparent practical necessities for performance of some functions at a different level.

\section{Fiscal Considerations}

The solution of many problems has as its base the need for adequate moneys to finance the services. In general, the Philadelphia 
metropolitan area is one of those in the nation well able to finance its own local and regional services. However, the older cities, particularly the core cities, are today confronted with needs for urban renewal on a scale so vast as to stagger the imagination. This renewal is essential to keep these older and core areas in reasonable competition with the newer cities and the suburban sections.

While the federal government may prove to be the primary source of fundamental economic renewal funds, every metropolitan problem requires money for its solution. For example, if transportation (transit and highway) needs are to be met, new sources of financing will be required. Also, with developing fundamental water resource problems, the means for financing their solution are not clear. Many other examples could be given of metropolitan needs for which adequate financing must be found.

Even if the basic economy of the region is such as to permit a degree of taxation or service charges sufficient to cope with the problems, the political and practical questions of the allocation of the benefits and charges involved in financing are serious, continuing and never fully or satisfactorily resolved. Means must be found for equitable assessment of costs of services to all jurisdictions benefiting.

\section{Vested Interests}

Government does not operate in a vacuum. It provides services. It employs people. It buys goods and services in the open market. It taxes persons-both natural and legal. It regulates activities of persons and corporations.

In the performance of each of the foregoing kinds of activities, law governs in part; but also, large amounts of discretion must be vested in the public officers to whom the performance of these functions is assigned.

In the process of exercising discretion, certain patterns are established. Joe is given a job; Jim has the garbage contract; Sam supplies the gasoline for municipal trucks; Susie is the tax assessor; and Josephine is the tax collector; the Ajax Corporation is assessed at twentyfive per cent of market value, and the Ajar Corporation is assessed at twenty-seven per cent, while widow Jones is assessed at twenty per cent; and the Blue Moose Greater Hamburger Joint, Inc., manages to get by without a few required license fees, and with a kindly health inspector who doesn't see too much wrong with the flies in the kitchen. Each of these persons, and many more, have something. Most of them know what they have. Some have, or fancy that they have, 
special advantage. Each may be concerned over the disturbance of the status quo.

Beyond the foregoing is an important fact applicable to taxpayers generally. While one minor civil jurisdiction operates its services economically and perhaps even frugally with consequent lesser tax or service charges, its neighboring jurisdiction may have a higher level of services or may operate extravagantly. In the first unit, therefore, there is a vested interest in the maintenance of the lower rates being paid.

Even the person who is enjoying no special privilege but just getting satisfactory service at a price satisfactory to him will want to be convinced what benefit he is to derive from a change in things as they are. The fact that many other sections of the region are confronted with unsatisfactory service in a given function and that a reorganization would be for the general good is not sufficient to cause him to want to give up, or even run the risk of sacrificing, his present satisfactory arrangement.

Finally, therefore, all of these facets of vested interest in the status quo must be recognized as powerful forces with which the proponent of change must deal, and deal successfully.

\section{Emotional Considerations}

Among the emotional factors constituting problems in structural change are the following.

\section{Apathy}

There are no adequate measures of the degree of concern which citizens have with respect to adequate solutions of their public problems. Nor is there fully adequate understanding of the factors which motivate one individual to a very serious concern, and another to an occasional interest, and still another to no interest at all. These are matters of human behavior which require very large amounts of research to be made cooperatively by the psychologists and the students of public problems, before meaningful and helpful knowledge is available.

Of course, it is recognized that persons with direct concern have greater interest than those with indirect concern. Thus, on the average, parents with children in public schools have a keener interest in school problems than do those without children. Also, people with automobiles are more concerned with the conditions of the road system than those rare citizens who do not have them. And so on, we must explore 
through the whole gamut of governmental activities and related interest groups.

With respect to the general or specific solutions to metropolitan problems today, it is probably a fair generalizaton to state that only a very small percentage of the citizens are aware that such problems are metropolitan or regional in character. They may be aware of the problem but that does not necessarily identify it as one with which other citizens in remote sections of the region are also concerned. Nor does it automatically suggest that a common effort at solution upon a regional, rather than strictly local, basis is appropriate.

Therefore, apathy, born largely out of ignorance, is a practical problem.

\section{Local Pride}

Closely related to apathy, but in some respects its antithetical opposite, is local pride. Local pride is helpful in the organization of many aspects of community life. Generally, it is a "plus" concept and one to be encouraged. Yet, like nationalism on the larger scale, it can-in a world so interdependent-become a significant obstacle to a wider approach to problems of a regional character. Local pride in the handling of what appears to be a wholly local problem can sometimes become a blinding force, particularly when skillfully handled by the professional. This blinding force is an important element in maintaining the status quo long after the conditions have disappeared which made a particular action rational.

Local pride is a peculiar phenomenon. This phenomenon of our emotional attachment to a wholly artificial area on a map, usually laid out before our time, is difficult to explain in purely logical concepts. Yet it is a real force which those assigned or dedicated to the solution of public problems on a regional basis must be willing and able to understand, to accept, and to provide for retention of its plus values in structural patterns evolved.

\section{Jealousy}

Jealousy, both individual and collective, may be a factor in modifying structural arrangements. The community having striven successfully to meet a particular problem, may have little tolerance for a solution which will call upon it to share the benefits derived from the application of its resources with neighboring communities.

Fear

Finally, there is fear-fear of the big city, fear of government, fear of bigness itself, fear of the development of new patterns for the 
performance of services that may run to dictatorship or national control, or may result in diminution of quality of service already found satisfactory.

\section{Communication}

Metropolitan areas are of course composed of people. It is these people who in the long run determine-through either positive or negative action-the course of solutions of public problems.

In a large metropolitan area, the problem of communication becomes extremely difficult. Most persons in such an area are obliged to rely upon a favorite metropolitan newspaper, a favorite radio or television station and one or two other principal communication devices for their knowledge of public problems. In such an area, it is only natural that the large mass media concentrate upon matters of greatest interest to the greatest number. Thus, in the Philadelphia metropolitan area, the lineage and radio time devoted to the problems of the city of Philadelphia, with about half the metropolitan area's population, far exceeds the combined lineage and time devoted to that of any one of the suburban areas, or perhaps indeed of all of them combined.

Residents of suburbia are serviced by certain local newspapers and occasionally radio stations or programs focused directly upon the local problems. Thus, the resident of the core city has little opportunity to become acquainted in depth with the problems of the region, even though he may become cognizant of the problems within the city. The resident of the suburb may become aware of the problems of the core city and of his own smaller community, but again may be ignorant of the broader implications of what he knows as it applies to the entire area.

With no thought of trying to sell people a "bill of goods," one of the very practical problems confronted by one who wishes to modify governmental structure in solution of metropolitan problems is that of effective and full communication to those citizens in the region with whom determination of the outcome will, in fact, lie-either through positive or negative action.

\section{Plain Cussedness}

Any catalogue of obstacles that must be overcome that omits plain cussedness is incomplete. The fact that the Democrats propose a solution may itself be sufficient for the Republicans to oppose the solution. The fact that one township is favorable to a proposal is frequently enough to insure the opposition of its neighbor. If one individual or organization proposes a specific thing, another individual or organiza- 
tion seems somehow to feel called upon to oppose it. This is a reality, not an illusion, and must be dealt with as such.

\section{The Odds and the Alternative}

One might conclude after reading the foregoing that the odds are so great as to make progress toward solution impossible. I do not think so.

The alternative to progress is stagnation, and stagnation is a prelude to ruin. Clearly our metropolitan problems can never be fully or finally "solved." We may allow conditions to continue to deteriorate until a crisis point is reached. Or we may commence now to develop and secure acceptance of answers likely to avoid such crisis.

Between where we are and where we may hope to go lies a kind of intensive research along a number of lines that has perhaps never been accomplished in American government. Concurrently, there is required a program of public information and discussion on the broadest possible scale. Out of such a process, I am convinced that we will again exercise our political genius in a manner worthy of our political heritage. 